Running head: MOVING AWAY FROM EXCLUSION

Moving Away from Disproportionate Exclusionary Discipline: Developing and Utilizing a

Continuum of Preventative and Instructional Supports

\author{
Rhonda N. T. Nese \\ Joseph F. T. Nese \\ University of Oregon \\ Connor McCroskey \\ Vancouver Public Schools \\ Paul Meng \\ University of Hawaii at Manoa \\ Danielle Triplett \\ Eoin Bastable \\ University of Oregon
}

2020

\begin{abstract}
Author Note
The research reported here was supported by the Institute of Education Sciences, U.S.

Department of Education, through Grant R305A180006 to University of Oregon. The opinions expressed are those of the authors and do not represent views of the Institute or the U.S. Department of Education. Address correspondence to Rhonda Nese, 1235 University of Oregon, Eugene, OR 97403, USA; rnese@uoregon.edu.
\end{abstract}

\title{
Citation
}

Nese, R. N. T., Nese, J. F. T., McCroskey, C., Meng, P., Triplett, D., \& Bastable, E. (In press). Moving away from disproportionate exclusionary discipline: Developing and utilizing a continuum of preventative and instructional supports. Preventing School Failure. 


\begin{abstract}
Ample scientific research has documented that exclusionary discipline practices are both ineffective for reducing unwanted behaviors and harmful to the long-term social and academic outcomes of students. Further, exclusionary discipline practices are especially harmful given their disproportionate use with students of color, students with disabilities, students living in poverty, and students who are struggling academically. To address these issues, the authors describe a process that uses instructional strategies as alternatives to exclusion. These instructional strategies hold promise for reducing the use of disproportionate discipline, improving student behavior and social skills, and strengthening student-teacher relationships.
\end{abstract}

Keywords: equity, exclusionary discipline, pbis, prevention, student support 


\section{Moving Away from Disproportionate Exclusionary Discipline: Developing and Utilizing a Continuum of Preventative and Instructional Supports}

Approaches to school discipline have evolved over time. Examples from generations ago conjure images of "dunce caps" and the writing of sentences on the chalkboard as means of punishing students for engaging in unwanted behaviors. Although such forms of punishment seem antiquated, humiliating, and may be used less frequently today, many schools continue to use other ineffective and damaging strategies when faced with unwanted behaviors in the classroom (Gershoff \& Font, 2016; U.S. Department of Education, 2010). Harmful discipline practices such as the exclusion of students from the learning environment have maintained a stronghold in schools regardless of their ineffectiveness at improving student behavior (Davis \& Jordan, 1994; Raffaele Mendez; 2003; Skiba, Chung, Trachok, Baker, Sheya, \& Hughes, 2014; Suh \& Suh, 2007; Tobin, Sugai, \& Colvin, 1996). The history of exclusionary discipline practices as well as research on the detrimental impact of such practices on student outcomes are further detailed, followed by a discussion of instructional strategies as alternatives to exclusion.

\section{Background on Exclusion}

The term exclusionary discipline in schools refers to disciplinary measures that remove students from instruction, such as sitting outside of class, in-school suspensions, out-of-school suspensions, and expulsions. It is difficult to trace the origin of exclusionary discipline practices in education, but the reports of its ineffectiveness and inequity are broad and consistent (Balfanz, Byrnes, \& Fox, 2015; Fabelo, Thompson, Plotkin, Carmichael, Marchbanks III, \& Booth, 2011; Losen \& Gillespie, 2012). In 1975, the US Supreme Court ruled that a public school must conduct a hearing before suspending a student, or it violates the due process clause of the Fourteenth Amendment in the US Constitution (Ellis, 1976). The majority opinion penned by 
Justice White argued that a suspension "could seriously damage the students' standing with their fellow pupils and their teachers as well as interfere with later opportunities for higher education and employment," an argument that was based partly on the fact that some colleges in the state asked high schools whether an applying student had ever been suspended (Goss v Lopez, 1975, p. $575)$.

In 1978, The Safe School Study was mandated by Congress to assess crime in schools, its associated material cost for repair, the means being used to prevent crimes in schools, and potential means for more effective crime prevention (National Institute of Education, 1978). The study was based on a mail survey of over 4,000 schools, an onsite survey of 642 schools, and case studies of 10 schools. The study reported that expulsions occurred less frequently than in the past, partly because of laws requiring school systems to provide education to all youth. Suspensions, however, were the most widely used disciplinary procedure, and most prevalent in large cities. The study reported that schools attempt to "handle problems of violence and disruption by removing troublesome youngsters either to special classes or to other schools," (p. 147) largely because of the "inability of the schools to find viable alternatives for dealing with them" (p. 147). Despite the wide-spread use of suspensions, few schools reported that suspensions were effective either as deterrents or as treatments.

In the face of these findings, Congress introduced the Gun-Free Schools Act (GFSA) in 1994, as part of the reauthorization of the Elementary and Secondary Education Act of 1965 (ESSA). The GFSA required states to have a law mandating one-year expulsion for weapon possession, and a referral of violating students to the criminal or juvenile justice system. This law has been criticized for being entirely punitive and not at all preventive, and research has overwhelmingly reported that these policies are theoretically flawed, detrimental to students and 
schools, and have no evidence to support a reduction in school violence (American Psychological Association Zero Tolerance Task Force, 2008; Losen, 2013; Mongan \& Walker, 2012; Skiba \& Knesting, 2001). Specifically, marginalized groups of children are the most likely to suffer the negative consequences of zero tolerance policies, as students of color and students with disabilities disproportionally receive exclusionary discipline practices for low-level, subjective behaviors unrelated to weapons or drugs (Curran, 2019; Skiba \& Knesting, 2001).

A report by the U.S. Departments of Education and Justice stated that nearly $60 \%$ of students were suspended or expelled between Grades 7 and 12 (U.S. Departments of Education and Justice, 2014). These students were nearly three times as likely to be in contact with the juvenile justice system the following year, and Black students were $31 \%$ more likely to receive exclusionary discipline than White and Hispanic students (U.S. Departments of Education and Justice, 2014). As a result, the U.S. Departments of Education and Justice announced in 2011 the Supportive School Discipline Initiative to encourage the use of school discipline practices that foster safe, supportive, and productive learning environments that aim to keep students in school. As of 2015, more than 20 states have revised their laws to require or encourage schools to limit the use of exclusionary discipline practices and implement supportive discipline strategies that rely on behavioral interventions (Steinberg \& Lacoe, 2017).

In sum, the conclusions of the 1978 Safe School Study about exclusionary discipline remain just as true today. The report states that there is "no evidence in this study that increasing the number of suspensions or expulsions will reduce the amount of crime in schools...however, there is considerable evidence that an active policy of firm, fair, and consistent discipline can reduce it" (p. 148).

\section{Rationale for Moving Away from Exclusion}


Decades of research have shown that exclusionary discipline practices are not only ineffective for addressing unwanted student behaviors, but the continued use of such practices are associated with negative social, behavioral, and academic outcomes for students (American Academy of Pediatrics Council on School Health, 2013) such as decreases in school engagement (Dishion \& Snyder, 2016), negative impacts on academic progress (Lacoe \& Steinberg, 2019), and contributions to inequitable outcomes for underrepresented students (Losen, Ee, Hodson, \& Martinez, 2015). These deleterious outcomes are particularly salient regarding out-of-school suspensions and expulsion. However, all forms of exclusionary discipline, including in-school suspensions and referrals that remove students from the classroom, are both detrimental to student outcomes and are applied disproportionality based on student characteristics such race, ethnicity, or disability status (Krezmien, Leone, \& Achilles, 2006; Losen, Hodson, Keith, Morrison, \& Belway, 2015; McIntosh, Girvan, Horner, \& Smolkowski, 2014; Wallace, Goodkind, Wallace, \& Bachman, 2008).

Negative impact on academic progress. One of the biggest detriments of exclusionary discipline practices is that they remove students from the instructional environment, thus limiting students' access to academic instruction as well as opportunities for social development (McIntosh \& Goodman, 2016; U.S. Departments of Education and Justice, 2014). One study showed that the use of a cross-class time-out intervention significantly reduced teacher ratings of unwanted behavior, but also reduced academic achievement amongst the students who were excluded from class (Benner, Nelson, Sanders, \& Ralston, 2012). Another study examining academic outcomes for students in Philadelphia found that just one out-of-school suspension decreased math and reading achievement on state testing for suspended students, with students' chances of scoring proficient on the state math exam falling by about 2 percentage points if they 
were suspended, and students' test scores fell even further the more days they were suspended (Lacoe \& Steinberg, 2019). Similar findings were documented in a study examining test scores among California students (Hwang, 2018). The study also revealed the decline in academic progress that individual students experienced as the number of exclusionary disciplines they received increased, documenting that multiple suspensions were associated with lower math and English language arts achievement even after controlling for differences between students (Hwang, 2018).

As students fall further behind academically, academic tasks may become more difficult which in turn might lead to more unwanted behaviors from students seeking to escape challenging academic responsibilities (Arcia, 2006; Tobin et al., 1996). Over the course of a students' academic career and beyond, the use of exclusionary discipline has been shown to affect grade retention, school dropout rates, and increase the likelihood of adult incarceration (American Academy of Pediatrics Council on School Health, 2013; Fabelo et al., 2011; Noltemeyer, Ward, \& Mcloughlin, 2015). Balfanz, Byrnes, and Fox (2015) found that a single out-of-school suspension in ninth grade was associated with a 50\% increase in dropping out and a $19 \%$ decrease in enrollment in postsecondary education.

Disproportionate use with underrepresented students. Exclusionary discipline contributes to racial inequities in school discipline practice (e.g., Davis \& Jordan, 1994; KewelRamani, Gilbertson, Fox, \& Provasnik, 2007; Skiba et al., 2014; Mattison \& Aber, 2007; Skiba, Michael, Nardo, \& Peterson, 2002; Wallace et al., 2008). Students of color, particularly Black students, disproportionately receive more out-of-school suspensions than their White peers (McIntosh et al., 2014). Furthermore, a national study of secondary schools found that while 7\% of White students were suspended at least one time, $11 \%$ of Hispanic/Latino students, $12 \%$ of 
American Indian students, and 23\% of Black students were suspended (Losen, Hodson, et al., 2015). And while $18 \%$ of students with disabilities were suspended, one in five districts in the United States suspended over 50\% of its Black male secondary students with disabilities (Losen, Ee, et al., 2015).

Although racial disparities in exclusionary discipline practices have been attributed to variables such as poverty or racial differences in base rates of unwanted student behaviors, multiple empirical studies have shown that race remains a significant predictor of school exclusion, even when controlling for these variables (Anyon et al., 2014; Bradshaw, Mitchell, O'Brennan, \& Leaf, 2010; Lee et al., 2011; Wallace et al., 2008). Contrary to the idea that exclusion policies and procedures are "race-neutral," emerging studies are showing that racial disparities in exclusionary discipline may be affected by the influence of implicit bias on disciplinary decision making, particularly related to subjective behaviors such as disrespect and defiance (Skiba et al., 2002; Smolkowski, Girvan, McIntosh, Nese, \& Horner, 2016). Other research has reported as much as two-fifths of the variance in the racial achievement gap is attributable to racial differences in suspension rates (Morris \& Perry, 2016).

Given the prevalence of exclusionary practices in schools and the detrimental impacts of such practices on student outcomes, it is important that educators be provided with strategies for promoting prosocial skills as well as strategies for responding to unwanted behaviors. One approach to reduce the negative costs associated exclusionary practices is to enhance the use of proactive, instructional approaches across school settings (Lin et al., 2013; Sterling Turner \& Watson, 1999). As such, it is valuable to examine instructional practices that facilitate the reduced need for and use of exclusionary discipline practices in schools. 
Negative impact on student behavior and school climate. In theory, exclusionary discipline should reduce unwanted behaviors through the principle of punishment (i.e., removing a preferred activity or item from a student in order to decrease the unwanted behavior; Ryan, Sanders, Katsiyannis, \& Yell, 2007). To be effective, the use of exclusion requires that the immediate environment be reinforcing for the student (Sterling Turner \& Watson, 1999). When the student does not experience the activity or school context as reinforcing, then exclusion from school is less likely to reduce unwanted behaviors. For example, if the school context is perceived as more aversive than a student's home or neighborhood, then exclusion from school may serve to reinforce unwanted behaviors (Maag, 2001). In practice, if a student finds a class assignment aversive, the student may exhibit unwanted behaviors (e.g., disruption) to avoid or escape the activity. Under these circumstances, teacher use of exclusionary practices may be counterproductive and could escalate a student's unwanted behaviors. As such, school personnel need to build strategies to make the classroom and general school environment more positive and reinforcing for students (Ryan et al., 2007). Unfortunately, exclusion can be reinforcing for school staff as well which may in turn create a behavior pattern in which students and teachers are continually reinforced for avoiding each other as well as the classroom activities (Dishion \& Snyder, 2016; McIntosh, Horner, Chard, Dickey, \& Braun, 2008). Furthermore, the American Psychological Association found that the negative effects of exclusionary discipline impact even the students not being excluded, as schools with high rates of out-of-school suspension have lower school-wide achievement and lower perceptions of school safety by the student body as a whole (American Psychological Association, 2008). In addition, research has found that receipt of out-of-school suspensions is also a significant predictor of future antisocial behavior, even when controlling for individual risk factors (e.g., antisocial behavior, deviant peer group 
membership; Hemphill, Toumbourou, Herrenkohl, McMorris, \& Catalano, 2006; Lee, Cornell, Gregory, \& Fan, 2011).

\section{What We Can Do: Alternatives to Exclusionary Discipline}

The detrimental effects of exclusionary discipline on student outcomes have driven many stakeholders to begin developing and using instructional and restorative alternatives with the goals of helping students develop the skills they need to succeed in school while simultaneously improving their relationships with their teachers and fellow students. This section outlines a few strategies within a continuum of supports. Strategies include preventative supports such as building relationships with students and using logical and functional responses to unwanted behaviors in the classroom, as well as reactive supports such as implementing graduated discipline systems where exclusion is reserved for the most concerning behaviors, and using instructional and restorative alternatives when students are removed from the classroom. The process by which intervention strategies are layered and intensified within a multi-tiered framework that includes individualized supports for students with the greatest needs is also discussed.

\section{Building Relationships}

As Delpit proclaimed in her book Other People's Children (1995), effective teaching begins with the establishment of relationships between the teacher and students. Building relationships with students (e.g., positive climate, teacher sensitivity, regard for student perspectives) can have a significant and positive effect on decreasing the use of exclusionary and disproportionate discipline practices. Understanding how to effectively build relationships across age groups, cultural backgrounds, and student interests can be a daunting task for any educator, novices in particular. A teacher's capacity to build relationships can be supported through 
establishing a safe classroom environment in which students learn how to be respectful and kind to one another. Positive classroom culture is strongly grounded in respectful relationships and student engagement allowing each child an environment of care, calm, support, and respect where they will succeed (Duong et al., 2019; Patrick, Turner, Meyer, \& Midgley, 2003).

The relationships teachers build with their students must be made explicit and highlighted at the beginning of the year, and every day after that. Students must clearly understand that their teacher is a real person, one who invests in such practices such as greeting them by name at the door every day or as a group at the start of class. This personal approach to teaching and behavior management is what allows students to trust and learn from their teacher. This approach is supported by Benard (2004) and Henderson and Milstein (1996) as they noted that caring relationships with adults and peers (e.g., teaching social skills, establishing unconditional positive regard, creating a culture of care and respect, consistently providing care and support) serves as a critical feature of positive school environments.

Teachers' ability to build relationships with students extends past their own personal approaches and hinges on the individual relationships students build with each other. This creation of a safe classroom environment must be facilitated and nurtured by the teacher (Duong et al., 2019). Students need opportunities to get to know one another, learn how to be respectful and kind, and practice interacting in a classroom full of diverse thoughts, backgrounds, and individuals. Positive classroom culture is strongly grounded in respectful relationships and student engagement allowing each child an environment of care, calm, support, and respect where he or she will succeed (Patrick, Turner, Meyer, \& Midgley, 2003).

Creating a collectivist classroom is one way to empower students to support each other and emphasize the relational aspect of the classroom and school. Collectivism refers to a set of 
values where students are taught to be helpful to each other, contribute to the success of the class, and adhere to group values and norms (Rothstein-Fisch, Greenfield, \& Trumbull, 1999). There are many ways to create a classroom environment that embraces student gifts and challenges; strategies include (a) involving students in group activities, (b) creating a sense of camaraderie, and (c) using student leadership as a way to model classroom values (Kaur \& Noman, 2015). Figure 1 provides a few examples of how teachers can build relationships with their students through simple strategies in the classroom.

Understanding students' backgrounds and building caring classroom communities is the foundation for reducing exclusionary and disparate behavior management practices. Bondy and colleagues noted, "The caveat is that the expressed emotions and demonstrations of care must be genuine, or the students will disregard the teacher's attempt to build a relationship" (2007, pg. $331)$.

\section{Logical Responses to Student Behavior}

Function-based and logical responses to unwanted student behavior first ensure the safety of everyone present in the classroom, and then incorporate the function of the behavior. The four core functions of unwanted behavior identified consistently in the literature are: obtain something (tangible), avoid something or someone (escape/avoid), obtain attention, and sensory reinforcement (Carr, 1994; Sugai et al., 2000). Logical approaches to managing unwanted behavior emphasize the antecedents and consequences of unwanted student behavior. When a student engages in disruptive behavior, a teacher considers the context of the classroom immediately prior to the disruption and what typically occurs following such disruption. Perhaps a new task has been assigned and upon further reflection it is clear that the student engaging in the disruptive behavior is not sufficiently fluent with the academic repertoire required for this 
assignment. If the student has experienced a history of removal from the educational setting following disruptive behavior, it is quite likely that the function of the behavior is to avoid the assignment. If the teacher proceeds as usual (removing the student from instruction), the disruptive behavior will be reinforced. If the teacher finds an alternative method of addressing the behavior that is consistent with the hypothesized function (avoidance), the behavior will be less likely to occur in the future. If a student engages in disruptive book dropping to avoid a portion of their English lesson, the response should not include removal of the demands of the English lesson, but rather supports to both assist the student with the work of the English lesson and to communicate the need for a break appropriately when the student begins feeling overwhelmed. Similarly, if a student engages in talk-outs to obtain attention from the teacher, the response should omit or at least minimize teacher attention. A brief re-direction without eye contact or a verbal/gestural prompt for the student to raise their hand would provide support and acknowledgement while minimizing teacher attention. Furthermore, the student who wants attention can access attention by doing the right thing. For example, if a student completes their assignment quietly, the teacher can announce that the student earned 5 minutes of extra recess for the whole class. Similarly, if a student engages in unwanted behavior immediately following removal of a preferred item, and ceases the behavior when the item is made available again, it is likely that the behavior serves a tangible function, which is to say the behavior occurs when the student wants a particular item. Figure 2 provides a few more examples of logical responses to unwanted behaviors.

The essential mindset for adopting a functional or logical approach to managing student behavior is the notion that behavior communicates students' needs. By interpreting student behavior as an expression of a student's current unmet needs, we are able to design interventions 
that meet these needs and reduce the likelihood of unwanted behavior in the future by teaching students the skills they need to proactively get their needs met in appropriate ways (Cook et al., 2018). When we teach students to communicate their needs in appropriate ways as an integral part of a function-based intervention, we are both ensuring the maximal effectiveness of our intervention efforts and honoring the dignity of the individual we are supporting (Carr \& Durand, 1985).

There are a variety of alternatives to removal from the instructional environment in situations that involve escape- or avoidance-maintained behaviors. Teaching a student new skills to request help (in a discreet manner) may be critical for students who avoid types of work with which they have previously experienced failure. Prompting these students to engage in helpseeking behaviors when signs of emotional distress or frustration first begin to appear may be another critical aspect of supporting their success in the classroom.

\section{Function-based Consequences on a Continuum}

Disciplinary consequences must be predictable and equitable to be more effective in practice. Specifically, consequences should recognize that students have individual needs that are based on their backgrounds and experiences, thus equitable consequences address the specific needs of each student (Cook et al., 2018; Lashley \& Tate, 2009). Further, these consequences should exist on a continuum that is engaged by the teacher based upon the intensity, duration, and frequency of the behavior of the student, and with the hypothesized function of the behavior taken into account. Initial consequences to student misbehavior include strategies like redirection, prompting, restating the expectations, removing distractions, and adjusting teacher proximity to the student. Next level consequences include practices like conferencing, reteaching, writing an apology letter, loss of privilege, restitution (e.g., clean-up, apology), 
removal to a partner classroom to complete work, phone call home, or an office discipline referral. It is important to keep graduated discipline systems progressively aligned (more intensive for more intense or chronic behavior), and logical (addressing both the function and the outcome of the behavior; i.e., an apology for name-calling along with brief re-teaching of expectations and appropriate ways to engage peers).

\section{Instructional Supports during Classroom Removal}

For students who do require a break from the classroom, it is vital that instructional supports be implemented that target relationship building, behavioral coaching, and academic remediation. The Inclusive Skill-building Learning Approach (ISLA; Nese, 2016) intervention is an example of a strategy that specifically addresses the instructional supports necessary for students to productively leave the classroom and return to class after receiving the necessary supports. This alternative to exclusionary discipline practices is aimed at improving student social and behavioral problem-solving, teacher and administrator practices, and student-teacher relationships while reducing the amount of instructional time lost. In a recent study of the preliminary pre- and post-impacts of ISLA, participating middle schools saw a $24 \%$ reduction in office discipline referrals, a $92 \%$ reduction in the minutes of instruction lost to exclusionary discipline, and strong effect sizes across all dependent variables including in-school and out-ofschool suspensions, demonstrating that ISLA has the potential to be an effective school-wide intervention (Nese, Bastable, Gion, Massar, Nese, \& McCroskey, in press). Staff members rated the ISLA intervention favorably, with mean scores for each item on the Primary Intervention Rating Scale (PIRS; Lane, Robertson, \& Wehby, 2002) ranging from 4.89 to 5.70 on a six-point Likert scale. 
The ISLA intervention focuses on systems to support implementation and instructional supports to build student behavioral skills. ISLA begins with a systems-level perspective that aims to provide a school-wide approach to prevention and improved school climate. Classroom practices, such as relationship building, teaching class-wide expectations, and using logical responses to unwanted behaviors are prioritized in an effort to reduce instances in which exclusion might have previously been used. These preventative practices are followed by targeted instructional supports for students in need of further support. These students receive coaching and support when they exhibit unwanted behavior that requires removal from the classroom environment. When a student receives a behavioral referral, a process is used to quickly provide the student with supports and reintroduce them to the classroom. First, a support staff member conducts a student-guided functional behavioral assessment, allowing for a better understanding of the problem and the student's perspective on the situation. The staff member then helps the student identify an appropriate replacement behavior, and more importantly, practices the behavior with the student. The staff member and student then complete a guided Reconnection Conversation Card and rehearse the conversation to prepare the student for reentry back into the classroom. Last, the student is escorted back to class and supported through the Reconnection Conversation with their teacher. This process was developed to provide immediate supports to students, to be time efficient, and to provide effective social skills coaching that targets the development and refinement of positive adaptive behaviors and reinforcement of prosocial skill use (Botvin, 2000; Chamberlain, 2003; Gresham, 2002). Figure 3 demonstrates what this model looks like in practice, from the preventative school-wide systems (i.e. building relationships, graduated and logical responses) that reduce the likelihood that students will be 
sent out of class to begin with, to the instructional strategies provided to students when they are in need of further support outside of the classroom.

\section{Using Tiered Supports for Students in Need}

The essential logic of multi-tiered systems of support (response to intervention and positive behavior supports) is that generally effective practices must be in place for everyone and that once these base layer supports are effectively implemented, the significant majority of students within a given setting will be successful (e.g., 80\%; Sugai et al., 2000). Beyond this base level, additional supports can be layered to more effectively and efficiently support those with greater needs. For those whose behavior does not respond sufficiently to the base level of support, a secondary level is added with increased intensity, but significant attention to efficiency (e.g., group delivery; $\sim 15 \%)$. For the small minority $(\sim 5 \%)$ of students who are still not successful with this level of support, intensive individualized supports are indicated.

Carr et al. (2002) outlined the core features of Positive Behavior Supports (PBS) to include a comprehensive lifestyle change, a lifespan perspective, ecological validity, stakeholder participation, social validity, systems change and multicomponent interventions, emphasis on prevention, flexibility in scientific practices, and multiple theoretical perspectives. The inclusion of these elements as core features is supported by several other papers on the topic of PBS, indicating a reasonable degree of consensus in the field pertaining to how it is defined (Sugai \& Horner, 2002; Tincani, 2007). Research on the effectiveness on PBS in schools has been quite thorough, indicating positive outcomes across numerous relevant dependent measures.

School-wide Positive Behavioral Interventions and Supports (SWPBIS) is one instance of systemic application of PBS that has garnered a great deal of attention in the research community. It incorporates the same values and key features, but with special emphasis placed 
on the usage of a tiered system of support and application of behavioral principles to achieve desired behavioral outcomes for all school children (Sugai et al., 2000). Applied systematically, SWPBIS have demonstrated effectiveness reducing unwanted behavior and increasing appropriate behavior (Luiselli, Putnam, Handler, \& Feinberg, 2005; Sugai \& Horner, 2002; Warren et al., 2006). Specific improvements documented after just a single year include over $20 \%$ reduction in office disciplinary referrals and over $50 \%$ reduction in short-term suspensions (Warren et al., 2006). Further, benefits for the holistic implementation of SWPBIS include increased instructional time and improved student achievement (Luiselli, et al., 2005; Scott \& Barrett, 2004). Additional documented improvements include reduction of serious unwanted behaviors (e.g., vandalism, violence), and increased student engagement during instruction (McCurdy, Mannella, \& Eldridge, 2003). Further, the mean number of students meeting "at-risk" criteria has been shown to decrease following the systematic implementation of SWPBIS (Ervin, Schaughency, Matthews, Goodman, \& McGlinchey, 2007). Last, in an extensive review of the literature, Sugai \& Horner (2002) found that aversive-based systems of behavior management which exist in many schools have at best short-lived positive outcomes associated with their use, and do not result in the type of sustaining positive outcomes desired of such systems. By layering supports across tiers from universal through intensive, educators can meet the varied needs of all students.

\section{Tier 3 Individualized Supports}

For students whose behaviors do not respond to the universal and targeted interventions provided by the school, individualized plans of support must be developed to ensure that students are receiving the behavioral programming necessary to move them toward the lower levels of intervention and prevention. Tier 3 intervention should complement the existing interventions 
and strategies that have been working for the student, while adding an additional layer of highly personalized support.

This level of intervention can include function-based behavioral interventions, explicit and systematic instruction for the student on the use of replacement behaviors instead of unwanted behaviors, a change to the environment, or some combination of the above. Individualized self-management instruction and practice is an example of a way to support students' unwanted behaviors, while still providing positive reinforcement and academic engagement opportunities. Teachers can implement this intervention, and classroom peers can support students who exhibit unwanted behaviors through self-rating reflections and positive praise. Christensen and colleagues (2004) found that teachers had more time to engage in instruction when they utilized classroom peers as helpers in a self-management intervention, in which the peers performed the matching and point-giving portions of the intervention with their fellow students. This resulted in improved student behavior and decreased teacher involvement in the intervention.

It is important to note that implementing evidence-based practices at this level requires collaboration, buy-in, and professional development for school staff and administrators who are primarily responsible for the delivery of the intervention (Algozzine et al., 2012). In addition, the student's cultural context should be considered. Customs, routines, and experiences should be clearly understood before individual programming is implemented. School and community factors will also play a part when such intensive services are developed and delivered. Parent involvement has been found to support students' educational and social success (Liew, Kwok, Chang, Chang, \& Yeh, 2014) and decrease the amount of unwanted behaviors observed at school (El Nokali, Bachman, \& Votruba-Drzal, 2010). Ensuring that families understand the plan and 
intervention, learning family and community histories, and prioritizing language and ethnicity considerations will all help to facilitate a successful Tier 3 intervention.

\section{Conclusion}

Moving schools away from using harmful exclusionary discipline practices often takes time and a philosophical shift. Such practices have been deeply embedded in our education systems for generations and can be reinforcing for adults when used in situations where they feel all resources and alternatives have been exhausted. Simply put, change is often difficult. However, educational institutions present the greatest potential for equalizing opportunities and improving outcomes for all students, especially those who have historically received disproportionate exclusionary discipline (Green, Maynard, \& Stegenga, 2018). Therefore, it makes sense for schools to prioritize the development and implementation of instructional alternatives to exclusionary practices, given that setting students up for success in school and beyond aligns directly with the goals and missions of almost every school and school district in the United States. The most effective alternatives to exclusion involve reconnecting, reteaching, reinforcing, and rebuilding relationships with students in an effort to increase student engagement, academic achievement, prosocial behaviors, and resiliency. These are skills that will serve our students for the rest of their lives. In order for students to benefit from these skills, they must first have the chance to access positive, predictable, and safe learning environments where they can engage in meaningful instruction and skill development with educational staff as well as peers that truly care about them and their future (Green et al., 2018). 


\section{References}

Algozzine, B., Wang, C., White, R., Cooke, N., Marr, M. B., Algozzine, K., \& Duran, G. Z. (2012). Effects of multi-tier academic and behavior instruction on difficult-to-teach students. Exceptional Children, 79, 45-64. doi: 10.1177/001440291207900103

American Academy of Pediatrics Council on School Health. (2013). Policy statement: Out-ofschool suspension and expulsion. Pediatrics, 131, e1000-e1007. doi: 10.1542/peds.20123932

American Psychological Association. (2008). Are zero tolerance policies effective in the schools? An evidentiary review and recommendations. American Psychologist, 63, 852862.

American Psychological Association Zero Tolerance Task Force. (2008). Are zero tolerance policies effective in the schools?: An evidentiary review and recommendations. The American Psychologist, 63, 852.

Anyon, Y., Jenson, J. M., Altschul, I., Farrar, J., McQueen, J., Greer, E., . . \& \& Simmons, J. (2014). The persistent effect of race and the promise of alternatives to suspension in school discipline outcomes. Children and Youth Services Review, 44, 379-386.

Arcia, E. (2006). Achievement and enrollment status of suspended students: Outcomes in a large, multicultural school district. Education and Urban Society, 38, 359-369.

Balfanz, R., Byrnes, V., \& Fox, J. (2015). Sent home and put off-track: The antecedents, disproportionalities, and consequences of being suspended in the 9th grade. In D. J. Losen (Ed.), Closing the school discipline gap: Research for policymakers (pp. 17-30). New York: Teachers College Press.

Benard, B. (Ed.) (2004). Resiliency: What we have learned. San Francisco: WestEd. 
Benner, G. J., Nelson, J. R., Sanders, E. A., \& Ralston, N. C. (2012). Behavior intervention for students with externalizing behavior problems: Primary-level standard protocol. Exceptional Children, 78, 181-198.

Bondy, E., Ross, D. D., Gallingane, C., \& Hambacher, E. (2007). Creating environments of success and resilience: Culturally responsive classroom management and more. Urban Education, 42, 326-348.

Botvin, G. J. (2000). Preventing drug abuse in schools: Social and competence enhancement approaches targeting individual-level etiologic factors. Addictive Behaviors, 25, 887-897.

Bradshaw, C. P., Mitchell, M. M., O'Brennan, L. M., \& Leaf, P. J. (2010). Multilevel exploration of factors contributing to the overrepresentation of black students in office disciplinary referrals. Journal of Educational Psychology, 102, 508-520.

Carr, E. G. (1994). Emerging themes in the functional analysis of unwanted behavior. Journal of Applied Behavior Analysis, 27, 393-400. doi: 10.1901/jaba.1994.27-393

Carr, E. G., Dunlap, G., Horner, R. H., Koegel, R. L., Turnbull, A. P., Sailor, W.,...\& Fox, L. (2002). Positive behavior support: Evolution of an applied science. Journal of Positive Behavior Interventions, 4, 4-16. doi: 10.1177/109830070200400102

Carr, E. G. \& Durand, V. M. (1985). Reducing behavior problems through functional communication training. Journal of Applied Behavior Analysis, 18, 111-126. doi: 10.1901/jaba.1985.18-111

Chamberlain, P. (2003). Treating chronic juvenile offenders: Advances made through the Oregon multidimensional treatment foster care model. Washington, DC: American Psychological Association. 
Christensen, L., Young, K. R., \& Marchant, M. (2004). The effects of a peer-mediated positive behavior support program on socially appropriate classroom behavior. Education \& Treatment of Children, 27, 199-234.

Cook, C. R., Duong, M. T., McIntosh, K., Fiat, A. E., Larson, M., Pullman, M. D., \& McGinnis, J. (2018). Addressing discipline disparities for black male students: Linking malleable root causes to feasible and effective practices. School Psychology Review, 47, 135-152.

Curran, F. C. (2019). The law, policy, and portrayal of zero tolerance school discipline: Examining prevalence and characteristics across levels of governance and school districts. Educational Policy, 33, 319-349.

Davis, J. E. \& Jordan, W. J. (1994). The effects of school context, structure, and experiences on African American males in middle and high schools. Journal of Negro Education, 63, 570-587. doi: $\underline{10.2307 / 2967296}$

Delpit, L. (1995). Other people's children: Cultural conflict in the classroom. New York: New Press.

Dishion, T. J. \& Snyder, J. (Eds.). (2016). Handbook of coercive relationship dynamics: Basic mechanisms, developmental processes, and intervention applications. New York: Oxford Press.

Duong, M. T., Pullmann, M. D., Buntain-Ricklefs, J., Lee, K., Benjamin, K. S., Nguyen, L., \& Cook, C. R. (2019). Brief teacher training improves student behavior and student-teacher relationships in middle school. School Psychology, 34, 212-221.

Elementary and Secondary Education Act of 1965 (ESSA). (1965). Pub. L. 89-10.

Ellis, M. A. (1976). Procedural due process after Goss v. Lopez. Duke Law Journal, 2, 409-430. 
El Nokali, N. E., Bachman, H. J., \& Votruba-Drzal, E. (2010). Parent involvement and children's academic and social development in elementary school. Child Development, 81, 988-1005. doi: 10.11111/j.1467-8624.2010.01447.x

Ervin, R. A., Schaughency, E., Matthews, A., Goodman, S. D., \& McGlinchey, M. T. (2007). Primary and secondary prevention of behavior difficulties: Developing a data-informed problem-solving model to guide decision making at a school-wide level. Psychology in the Schools, 44, 7-18. doi: 10.1002/pits.20201

Fabelo, T., Thompson, M. D., Plotkin, M., Carmichael, D., Marchbanks III, M. P., \& Booth, E. A. (2011). Breaking schools' rules: A statewide study of how school discipline relates to students' success and juvenile justice involvement. New York, Council of State Governments Justice Center.

Gershoff, E. T. \& Font, S. A. (2016). Corporal punishment in US public schools: Prevalence, disparities in use, and status in state and federal policy. Social policy report, 30.

Goss v. Lopez (1975). 419 U.S. 565, 95 S. Ct, 729, 42.

Green, A. L., Maynard, D. K., \& Stegenga, S. M. (2018). Common misconceptions of suspensions: Ideas and alternatives for school leaders. Psychology in the schools, 55, 419-428. doi: 10.1002/pits.22111

Gresham, F. M. (2002). Teaching social skills to high-risk children and youth: Preventive and remedial strategies. In M. A. Shinn, H. M. Walker \& G. Stoner, (Eds.) Interventions for academic and behavior problems II: Preventive and remedial approaches (pp. 403-432). Bethesda, MD: NASP.

Guns Free School Act of 1994, 20 U.S. Code $§ 7961$. 
Hemphill, S. A., Toumbourou, J. W., Herrenkohl, T. I., McMorris, B. J., \& Catalano, R. F. (2006). The effect of school suspensions and arrests on subsequent adolescent antisocial behavior in Australia and the United States. Journal of Adolescent Health, 39, 736-744.

Henderson, N. \& Milstein, M. M. (1996). Resiliency in schools. Thousand Oaks, CA: Corwin Press.

Hwang, N. (2018). Suspensions and achievement: Varying links by type, frequency, and subgroup. Educational Researcher, 47, 363-374.

Kaur, A. \& Noman, M. (2015). Exploring classroom practices in collectivist cultures through the lens of Hofstede's Model. The Qualitative Report, 20, 1794-1811.

KewelRamani, A., Gilbertson, L., Fox, M., \& Provasnik, S. (2007). Status and trends in the education of racial and ethnic minorities (NCES 2007-039). Washington, DC: National Center for Educational Statistics, Institute of Education Sciences, U.S. Department of Education.

Krezmien, M. P., Leone, P. E., \& Achilles, G. M. (2006). Suspension race and disability: Analysis of statewide practices and reporting. Journal of Emotional and Behavioral Disorders, 14, 217-226.

Lacoe, J. \& Steinberg, M. P. (2019). Do suspensions affect student outcomes? Educational Evaluation and Policy Analysis, 41, 34-62.

Lane, K. L., Robertson, E. J., \& Wehby, J. H. (2002). Primary Intervention Rating Scale. Unpublished rating scale.

Lashley, C. \& Tate, A. S. (2009). A framework for educative, equitable, and empowering disciplinary practice. Journal of Special Education Leadership, 22, 24-35. 
Lee, T., Cornell, D., Gregory, A., \& Fan, X. (2011). High suspension schools and dropout rates for black and white students. Education and Treatment of Children, 34, 167-192.

Liew, J., Kwok, O., Chang, Y. P., Chang, B. W., \& Yeh, Y. C. (2014). Parental autonomy support predicts academic achievement through emotion-related self-regulation and adaptive skills in Chinese American adolescents. Asian American journal of psychology, 5, 214-222.

Losen, D. J. (2013). Discipline policies, successful schools, racial justice, and the law. Family Court Review, 51, 388-400.

Losen, D. J., Ee, J., Hodson, C., \& Martinez, T. E. (2015). Disturbing inequities: Exploring the relationship of discipline disparities for students with disabilities by race with gender with school outcomes. In D. J. Losen (Ed.), Closing the School Discipline Gap: Equitable Remedies for Excessive Exclusion (pp. 89-106). New York: Teacher's College Press.

Losen, D. J. \& Gillespie, J. (2012). Opportunities suspended: The disparate impact of disciplinary exclusion from school. Los Angeles, CA: Center for Civil Rights Remedies at The Civil Rights Project at UCLA.

Losen, D. J., Hodson, C., Keith, M. A., Morrison, K., \& Belway, S. (2015). Are we closing the school discipline gap? Los Angeles, CA: Center for Civil Rights Remedies at The Civil Rights Project at UCLA.

Luiselli, J. K., Putnam, R. F., Handler, M. W., \& Feinberg, A. B. (2005). Whole-school positive behavior support: Effects on student discipline problems and academic performance. Educational Psychology, 25, 183-198.

Maag, J. W. (2001). Rewarded by punishment: Reflections on the disuse of positive reinforcement in schools. Exceptional Children, 67, 173-186. 
Mattison, E. \& Aber, M. S. (2007). Closing the achievement gap: The association of racial climate with achievement and behavioral outcomes. American Journal of Community Psychology, 40, 1-12.

McCurdy, B. L., Mannella, M. C., \& Eldridge, N. (2003). Positive behavior support in urban schools: Can we prevent the escalation of antisocial behavior? Journal of Positive Behavior Interventions, 5, 158-170. doi: 10.1177/10983007030050030501

McIntosh, K., Girvan, E. J., Horner, R. H., \& Smolkowski, K. (2014). Education not incarceration: A conceptual model for reducing racial and ethnic disproportionality in school discipline. Journal of Applied Research on Children, 5, 1-22.

McIntosh, K. \& Goodman, S. (2016). Integrated multi-tiered systems of support: Blending RTI and PBIS. New York: Guilford Press.

McIntosh, K., Horner, R. H., Chard, D. J., Dickey, C. R., \& Braun, D. H. (2008). Reading skills and function of unwanted behavior in typical school settings. Journal of Special Education, 42, 131-147. doi: 10.1177/0022466907313253

Mongan, P. \& Walker, R. (2012). The road to hell is paved with good intentions: An historical, theoretical, and legal analysis of zero-tolerance weapons policies in American schools. Preventing School Failure: Alternative Education for Children and Youth, 56, 232-240.

Morris, E. W. \& Perry, B. L. (2016). the punishment gap: School suspension and racial disparities in achievement. Social Problems, 63, 68-86.

National Institute of Education (1978). Violent schools, safe schools: The safe school study report to the Congress (Vol. 1). U.S. Department of Health, Education and Welfare, National Institute of Education. 
Nese, R. N. T. (2016). The inclusive skill-building learning approach (ISLA). Educational and Community Supports, Eugene: OR.

Nese, R. N. T., Bastable, E., Gion, C., Massar, M., Nese, J. F. T., \& McCroskey, C. (In press). Preliminary analysis of an instructional alternative to exclusionary discipline. The Journal of At-Risk Issues.

Noltemeyer, A. L., Ward, R. M., \& Mcloughlin, C. S. (2015). Relationship between school suspension and student outcomes: A meta-analysis. School Psychology Review, 44, 224240.

Patrick, H., Turner, J., Meyer, D. K., \& Midgley, C. (2003). How teachers establish psychological environments during the first days of school: Associations with avoidance in mathematics. Teachers College Record, 105, 1521-1558.

Raffaele Mendez, L. M. (2003). Predictors of suspension and negative school outcomes: A longitudinal investigation. In Wald, J., Losen, D. J. (Eds.), New directions for youth development (pp. 17-34). San Francisco, CA: Jossey-Bass.

Rothstein-Fisch, C., Greenfield, P. M., \& Trumbull, E. (1999). Bridging cultures with classroom strategies. Educational Leadership, 56, 64-67.

Ryan, J. B., Sanders, S., Katsiyannis, A., \& Yell, M. L. (2007). Using time-out effectively in the classroom. Teaching Exceptional Children, 39, 60-67.

Scott, T. M., \& Barrett, S. B. (2004). Using staff and student time engaged in disciplinary procedures to evaluate the impact of school-wide PBS. Journal of Positive Behavior Interventions, 6, 21-27. doi: 10.1177/10983007040060010401

Skiba, R. J., Chung, C. G., Trachok, M., Baker, T. L., Sheya, A., \& Hughes, R. L. (2014). Parsing disciplinary disproportionality: Contributions of infraction, student, and school 
characteristics to out-of-school suspension and expulsion. American Educational Research Journal, 51, 640-670.

Skiba, R. J. \& Knesting, K. (2001). Zero tolerance, zero evidence: An analysis of school disciplinary practice. New Directions for Youth Development, 2001, 17-43.

Skiba, R. J., Michael, R. S., Nardo, A. C., \& Peterson, R. L. (2002). The color of discipline: Sources of racial and gender disproportionality in school punishment. The Urban Review, 34, 317-342. doi: 10.1023/A:1021320817372

Smolkowski, K., Girvan, E. J., McIntosh, K., Nese, R. N. T., \& Horner, R. (2016). Vulnerable decision points for disproportionate office discipline referrals: Comparisons of discipline for African American and White elementary school students. Behavioral Disorders, 41, 178-195. doi: http://dx.doi.org/10.17988/bedi-41-04-178-195.1

Steinberg, M. P., \& Lacoe, J. (2017). What do we know about school discipline reform? Assessing the alternatives to suspensions and expulsions. Education Next, 17, 44-53.

Sterling Turner, H., \& Watson, T. S. (1999). Consultant's guide for the use of time-out in the preschool and elementary classroom. Psychology in the Schools, 36, 135-148.

Sugai, G. \& Horner, R. (2002). The evolution of discipline practices: School-wide positive behavior supports. Child \& Family Behavior Therapy, 24, 23-50. doi: 10.1300/j019v24n01_03

Sugai, G., Horner, R. H., Dunlap, G., Hieneman, M., Lewis, T. J., Nelson, C. M., . . \& Ruef, M. (2000). Applying positive behavior support and functional behavioral assessment in schools. Journal of Positive Behavior Interventions, 2, 131-143.

Suh, S. \& Suh, J. (2007). Risk factors and levels of risk for high school dropouts. Professional School Counseling, 10, 297-306. 
Tincani (2007). Moving forward: Positive behavior support and applied behavior analysis. The Behavior Analyst Today, 8, 492-499.

Tobin, T., Sugai, G., \& Colvin, G. (1996). Patterns in middle school discipline records. Journal of Emotional and Behavioral Disorders, 4, 82-94.

U.S. Department of Education (2010). Summary of seclusion and restraint statutes, regulations, policies and guidance, by state and territory: Information as reported to the regional comprehensive centers and gathered from other sources. Washington, D.C. Retrieved from https://www2.ed.gov/policy/seclusion/summary-by-state.pdf

U.S. Departments of Education and Justice (2014). Dear Colleague Letter: Nondiscriminatory Administration of School Discipline. Washington, D.C. Retrieved from http://www2.ed.gov/about/offices/list/ocr/letters/colleague-201401-title-vi.html.

Wallace, J. M. J., Goodkind, S., Wallace, C. M., \& Bachman, J. G. (2008). Racial, ethnic, and gender differences in school discipline among U.S. high school students: 1991-2005. Negro Educational Review, 59, 47-62.

Warren, J. S., Bohanon-Edmonson, H. M., Turnbull, A. P., Sailor, W., Wickham, D., Griggs, P., \& Beech, S. E. (2006). School-wide positive behavior support: Addressing behavior problems that impeded student learning. Educational Psychology Review, 18, 187-198. doi: 10.1007/s10648-006-9008-1 
Teacher: When I interact with you, I am going to do so in a respectful way, I am going to listen to you, and I am going to encourage you. I also expect you to treat me and your classmates in the same way. That way

Modeling we can all learn together in a safe and positive classroom. I'm also human and I make mistakes, just like everyone else. And that's ok, we will all just practice owning our mistakes, making amends, and moving on.

If a friend said something rude to me, how could I respond? When someone bumps into you in the hall or lunchroom, what are some of the things you could do? If you get a bad grade on a quiz, how could you ask for clarification or help next time?

Choral responses Repeat after me! I will treat others like I want to be treated!

Humor If you need a break during class, all you have to do is raise your hand, make eye contact with me, and mouth "get me out of here."

Teacher: One thing you are going to notice when you're in my class is

Personal stories that I really like to sing and dance. So don't be alarmed if I hear some music and start hitting the dance floor.

Figure 1. Strategies for Building Relationships 


\begin{tabular}{|c|c|c|c|}
\hline Function & Instead of... & Try... & Teach... \\
\hline Escape/Avoid & $\begin{array}{l}\text { Sending student out of } \\
\text { class }\end{array}$ & $\begin{array}{l}\text { Offering additional help, } \\
\text { time to calm down, a } \\
\text { shorter assignment to } \\
\text { start with until the student } \\
\text { builds skill with the } \\
\text { required task. }\end{array}$ & $\begin{array}{l}\text { The student to ask } \\
\text { for help, self-calming } \\
\text { strategies, skills } \\
\text { needed to complete } \\
\text { assigned work }\end{array}$ \\
\hline $\begin{array}{l}\text { Teacher } \\
\text { Attention }\end{array}$ & $\begin{array}{l}\text { Reprimanding the } \\
\text { student verbally }\end{array}$ & $\begin{array}{l}\text { Quietly prompting the } \\
\text { student to get your } \\
\text { attention in a positive } \\
\text { way, avoiding eye contact } \\
\text { until appropriate behavior } \\
\text { is displayed. }\end{array}$ & $\begin{array}{l}\text { The student to raise } \\
\text { their hand }\end{array}$ \\
\hline Peer Attention & $\begin{array}{l}\text { Reprimanding the } \\
\text { student verbally }\end{array}$ & $\begin{array}{l}\text { Prompt the student to } \\
\text { repair the peer } \\
\text { relationship through } \\
\text { apology, re-teach } \\
\text { expectations, build in } \\
\text { additional partner work } \\
\text { time earlier in the day }\end{array}$ & $\begin{array}{l}\text { Initiate peer } \\
\text { interactions } \\
\text { appropriately, } \\
\text { recognize when they } \\
\text { are feeling lonely or } \\
\text { in need of attention, } \\
\text { seek attention } \\
\text { appropriately, wait } \\
\text { until appropriate } \\
\text { times to engage peers }\end{array}$ \\
\hline Tangible & $\begin{array}{l}\text { Delivering the desired } \\
\text { item/activity }\end{array}$ & $\begin{array}{l}\text { Provide an easier segue } \\
\text { activity (reading at desk) } \\
\text { from a preferred activity } \\
\text { (iPad) to the target } \\
\text { activity (workbook) }\end{array}$ & $\begin{array}{l}\text { Request desired } \\
\text { items/activities } \\
\text { appropriately, wait } \\
\text { until appropriate } \\
\text { times to engage } \\
\text { preferred items, } \\
\text { perform the target } \\
\text { activity with greater } \\
\text { fluency }\end{array}$ \\
\hline
\end{tabular}

Figure 2. Responding to Student Unwanted Behavior 


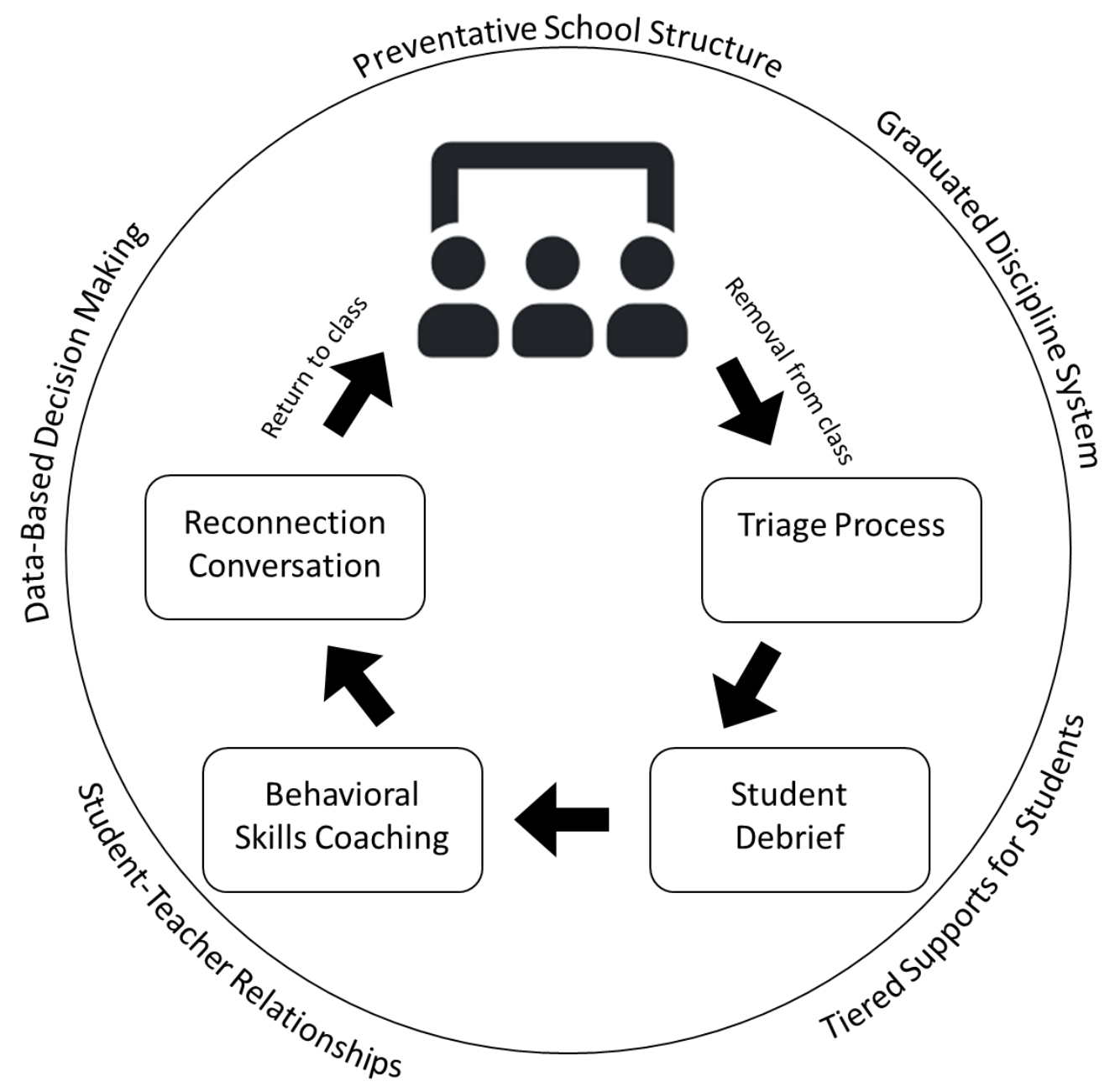

Figure 3. The ISLA Model of Support 